\title{
Efficacy of prophylactic cranial irradiation in patients limited-disease small-cell lung cancer who were confirmed to have no brain metastasis via magnetic resonance imaging after initial chemoradiotherapy
}

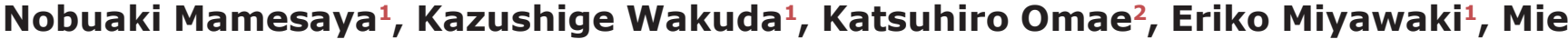

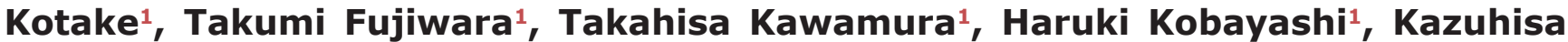 \\ Nakashima ${ }^{1}$, Shota Omori ${ }^{1}$, Akira Ono ${ }^{1}$, Hirotsugu Kenmotsu ${ }^{1}$, Tateaki Naito ${ }^{1}$, \\ Haruyasu Murakami ${ }^{1}$, Keita Mori ${ }^{2}$, Hideyuki Harada ${ }^{3}$, Masahiro Endo ${ }^{4}$, Takashi \\ Nakajima $^{5}$ and Toshiaki Takahashi ${ }^{1}$ \\ ${ }^{1}$ Division of Thoracic Oncology, Shizuoka Cancer Center, Shizuoka, Japan \\ ${ }^{2}$ Clinical Research Center, Shizuoka Cancer Center, Shizuoka, Japan \\ ${ }^{3}$ Division of Radiation Therapy, Shizuoka Cancer Center, Shizuoka, Japan \\ ${ }^{4}$ Division of Diagnostic Radiology, Shizuoka Cancer Center, Shizuoka, Japan \\ ${ }^{5}$ Division of Pathology, Shizuoka Cancer Center, Shizuoka, Japan \\ Correspondence to: Kazushige Wakuda, email: k.wakuda@scchr.jp \\ Keywords: small-cell lung cancer; limited disease; prophylactic cranial irradiation; brain metastases \\ Received: November 21, $2017 \quad$ Accepted: March 02, $2018 \quad$ Published: April 03, 2018 \\ Copyright: Mamesaya et al. This is an open-access article distributed under the terms of the Creative Commons Attribution License \\ 3.0 (CC BY 3.0), which permits unrestricted use, distribution, and reproduction in any medium, provided the original author and \\ source are credited.
}

\section{ABSTRACT}

Background: Prophylactic cranial irradiation (PCI) is recommended for patients with limited-disease small-cell lung cancer (LD-SCLC) who achieved good response to definitive chemoradiotherapy. However, most clinical studies lacked brain imaging scans before PCI. Our study aimed to investigate whether PCI has a survival benefit in patients who have no brain metastases (BM) confirmed via magnetic resonance imaging (MRI) before PCI.

Results: Eighty patients were included in this study. Sixty patients received PCI (PCI group) and 20 patients did not (non-PCI group). OS was not significantly different between the two groups. The median OS time was 4.3 years (95\% CI: 2.6 years-8.6 years) in the PCI group and was not reached (NR) (95\% CI: 1.9 years-NR) in the non-PCI group $(p=0.542)$. Moreover, no differences were observed in the 3 -year rates of PFS $(46.2 \%$ and $44.4 \%, p=0.720)$ and cumulative incidence of $B M$ $(24.0 \%$ vs. $27 \%, p=0.404)$.

Conclusions: Our result suggests that PCI may not have a survival benefit in patients with LD-SCLC confirmed to have no BM after initial therapy, even if patients achieve a good response to definitive chemoradiotherapy.

Patients and Methods: We retrospectively evaluated patients with LD-SCLC who were confirmed to have no BM via MRI after initial chemoradiotherapy at the Shizuoka Cancer Center between September 2002 and August 2015. The overall survival (OS), progression-free survival (PFS), and cumulative incidence of BM were estimated using the Kaplan-Meier method between patients who received PCI and those who did not. Propensity score matching was used to balance baseline characteristics. 


\section{INTRODUCTION}

Small-cell lung cancer (SCLC) is a rapidly disseminating cancer accounting for $13 \%-15 \%$ of all lung cancers $[1,2]$. Approximately two-thirds of SCLC cases are diagnosed with metastatic disease: extensive disease (ED) [1, 3], while the remaining one-third are diagnosed with limited disease (LD) curable via aggressive multimodality approach. The standard therapy for LD-SCLC is chemotherapy and concurrent thoracic radiotherapy (TRT) $[4,5]$. The chemotherapy regimen consists of cisplatin (CDDP) or carboplatin (CBDCA) with etoposide $[6,7]$. Although initial treatment for LDSCLC demonstrates high response rate, most cases have recurrences within 1 year, with the brain being among the frequent sites of metastasis. More than $50 \%$ of patients develop brain metastases (BM), and approximately $45 \%$ of those who achieve complete response (CR) to initial therapy will develop BM as the only site of relapse [8]. The prognoses of patients with SCLC who develop BM during treatment are significantly poorer than those who do not develop BM $[9,10]$. Therefore, prophylactic cranial irradiation (PCI) is expected to prolong overall survival (OS), and many randomized controlled trials have been conducted $[8,11-14]$. However, they individually found no significant improvement in OS. Meanwhile, metaanalyses of these trials have shown that PCI improves OS in patients with SCLC who achieved a CR to initial treatment with chemotherapy $[15,16]$. Auperin et al. [15] conducted a meta-analysis that assessed seven randomized trials that assessed the effects of PCI. Of the 987 patients, 847 patients $(86 \%)$ had limited disease. They found that PCI decreased the cumulative incidence of BM (relative risk: 0.46 ; $95 \%$ CI: $0.38-0.57 ; p<0.001$ ). The relative risk of death in the PCI group was 0.84 (95\% CI: $0.73-$ $0.97 ; p=0.01)$, which corresponds to a $5.4 \%$ absolute increase in 3-year survival (no-PCI group, $15.3 \%$; PCI group, 20.7\%). Based on this meta-analysis, the American Society of Clinical Oncology recommended PCI for patients with SCLC who achieve CR or partial response (PR) to initial therapy [17]. However, BM before PCI was not evaluated in most cases in these trials. Recently, a Japanese phase III randomized trial showed that PCI can reduce the incidence of BM but cannot improve the 3 -year OS among patients with extensive disease-small cell lung cancer (ED-SCLC) confirmed to have no BM via magnetic resonance imaging (MRI) before receiving PCI [18]. MRI is more sensitive for detecting BM than contrast-enhanced computed tomography (CT) [19], and MRI is the best assessment tool for choosing the optimal treatment approach for BM. Therefore, whether PCI has clinical benefit or not to patients with LD-SCLC who have no BM under MRI before PCI is controversial. Our study aimed to investigate whether PCI has survival benefit in patients with LD-SCLC confirmed to have no BM via MRI after initial chemoradiotherapy.

\section{RESULTS}

\section{Patient characteristics}

A total of 127 patients with LD-SCLC were indicated to receive definitive chemoradiotherapy. Of these, 47 patients were excluded because of developing BM during initial chemoradiotherapy $(N=9)$; receiving uncomplete chemoradiotherapy $(N=14)$; inadequate response to initial treatment or early disease progression $(N=10)$; second critical malignancy or unacceptable complicated diseases $(N=8)$; stage I disease at initial diagnosis $(N=2)$; and no brain MRI after initial treatment $(N=4)$. Finally, 80 patients were enrolled, and they were divided into the PCI group $(N=60)$ and non-PCI group $(N=20)$ (Figure 1). PCI was delivered at 25 Gy in 10 daily fractions to the whole brain. Patient characteristics are summarized in Table 1. At baseline, age, smoking history, the choice of platinum-containing drug, and the timing of TRT differed significantly between the two groups. Propensity score matching was performed as 1:1 match of the PCI and non-PCI group. After adjustment for propensity scores, 19 pairs were matched between two groups, and all covariates were well balanced among patients treated with and without PCI (Table 2). Patients in the non-PCI group did not receive PCI due to the following reasons: elderly age at initial treatment $(N=8)$; declined PCI against medical advice $(N=3)$; poor general status $(N=2)$; early relapse after evaluation to initial treatment $(N=1)$; and unknown reason $(N=6)$ (Figure 1).

\section{Survivals and brain metastases}

The length of follow-up did not differ significantly between the two groups: the median was 3.4 years (range, 0.6 years -12.6 years) in the PCI group and 3.0 years (range, 1.2 years-12.1 years) in the non-PCI group ( $p=0.608$ ). Figure 2 shows the survival curves after initial treatment. OS was not significantly different between the two groups: the median OS was 4.3 years (95\% CI: 2.6 years- 8.6 years) in the PCI group and not reached (NR) (95\% CI: 1.9 years-NR) in the non-PCI group (log-rank $p=0.542)$ (Figure 2A). The 1-year survival rate in the PCI and nonPCI group was $90 \%$ vs. $95 \%$, and the 3 -year survival rate was $57.3 \%$ vs. $59.2 \%$, respectively. Supplementary Table 1 showed no associations between the patient characteristics including receiving PCI, and OS in unmatched cohort (S1). After propensity score matching, PCI was not associated with OS prolongation: the median OS was 5.6 years $(95 \%$ CI: 2.5 years-NR) in the PCI group and NR (95\% CI: 2.2 years-NR) in the non-PCI group (log-rank $p=0.755$ ) (Figure 2B). Figure 3 shows the curves for progressionfree survival (PFS) and cumulative incidence of BM. No differences were observed in the 3-year rates of PFS and cumulative incidence of BM between the PCI and the nonPCI group: PFS, $46.2 \%$ and $44.4 \%(\log -\operatorname{rank} p=0.720)$; 
cumulative incidence of BM (24.0\% vs. $27.0 \%$, log-rank $p=0.404)$, respectively.

\section{Treatments after disease progression}

Furthermore, second-line chemotherapy for recurrence was administered to 27 (96.4\%) and 7 (70\%) patients in the PCI and non-PCI groups, respectively (Table 3). Radiation therapy for BM recurrences after the initial chemoradiotherapy with or without PCI was administered to $11(64.7 \%)$ and $6(75.0 \%)$ patients in the PCI and non-PCI groups, respectively (Table 3). All 6 patients in the non-PCI group chose whole brain radiation therapy. All remaining patients who had BM recurrences were administered up to third- or fourth-line salvage chemotherapy without cranial irradiation for BM. Leukoencephalopathy after PCI was observed in 1 patient in the PCI group. The patient chose the best supportive care after management for leukoencephalopathy because of deteriorating Eastern Cooperative Oncology Group Performance Status (ECOG-PS) when the recurrence progressed.

\section{DISCUSSION}

PCI improves the survival and reduces the incidence of BM in patients with SCLC $[15,16,20]$. These findings indicate that PCI is recommended for LD-SCLC patients who have a good response to initial therapy. However, this recommendation was made based on studies in which brain imaging was not a standard method in initial staging or follow-up. The prevalence of detected BM during
SCLC treatment was $10 \%$ in the CT era and $24 \%$ in the MRI era [21]. Manapov et al. [10] also reported that $13 / 40(32.5 \%)$ patients with LD-SCLC who achieved CR to initial chemoradiotherapy developed BM as confirmed on contrast-enhanced cranial MRI before PCI. Of the 13 patients, 11 had asymptomatic brain metastases. These data indicate that asymptomatic BM might be missed if brain MRI is not performed after initial therapy. Therefore, we performed this retrospective study to evaluate the efficacy of PCI for LD-SCLC patients with no evidence of BM confirmed on MRI before PCI administration. PCI reduces the incidence of symptomatic $\mathrm{BM}$ and prolongs disease-free survival and OS in patients with ED-SCLC who responded to chemotherapy [22]. However, in this randomized trial, brain imaging was not part of standard staging and follow-up procedures, unless BM was suspected. PCI without restaging MRI is likely to result to overtreatment for patients without BM or undertreatment for patients with BM. A Japanese phase III randomized trial showed that PCI did not improve OS in ED-SCLC patients who achieved CR or PR to initial chemotherapy without confirmed BM on MRI before receiving PCI [18]. Thus, cranial irradiation as prophylaxis was shown to have no clinical benefit. In our study, a similar result regarding OS in patients with LD-SCLC who achieved CR or good PR to initial chemotherapy without BM confirmed on MRI before receiving PCI was also achieved.

However, the age, smoking history, choice of platinum-containing drug, and timing of TRT were different between patients in the PCI and non-PCI group. In general, elderly patients with lung cancer have poor prognosis [23]. Furthermore, delayed TRT with

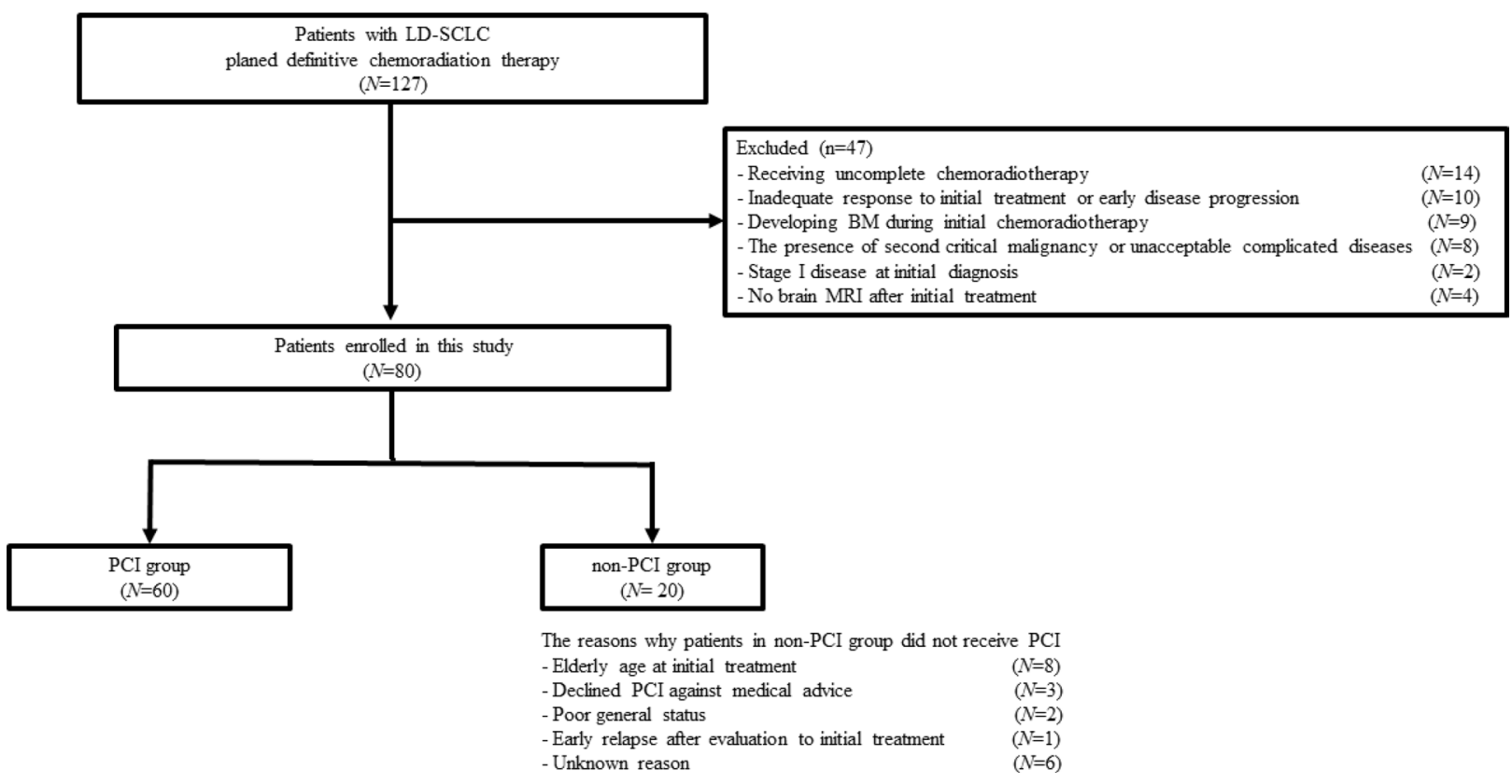

Figure 1: Flow diagram of the planned chemoradiotherapy for 127 patients with LD-SCLC. 47 patients were excluded because of some reasons and 80 patients were enrolled in this study. They were divided into the PCI group $(N=60)$ and non-PCI group $(N=20)$. Abbreviation: LD-SCLC, limited disease-small cell lung cancer; PCI, prophylactic cranial irradiation; BM, brain metastases. 


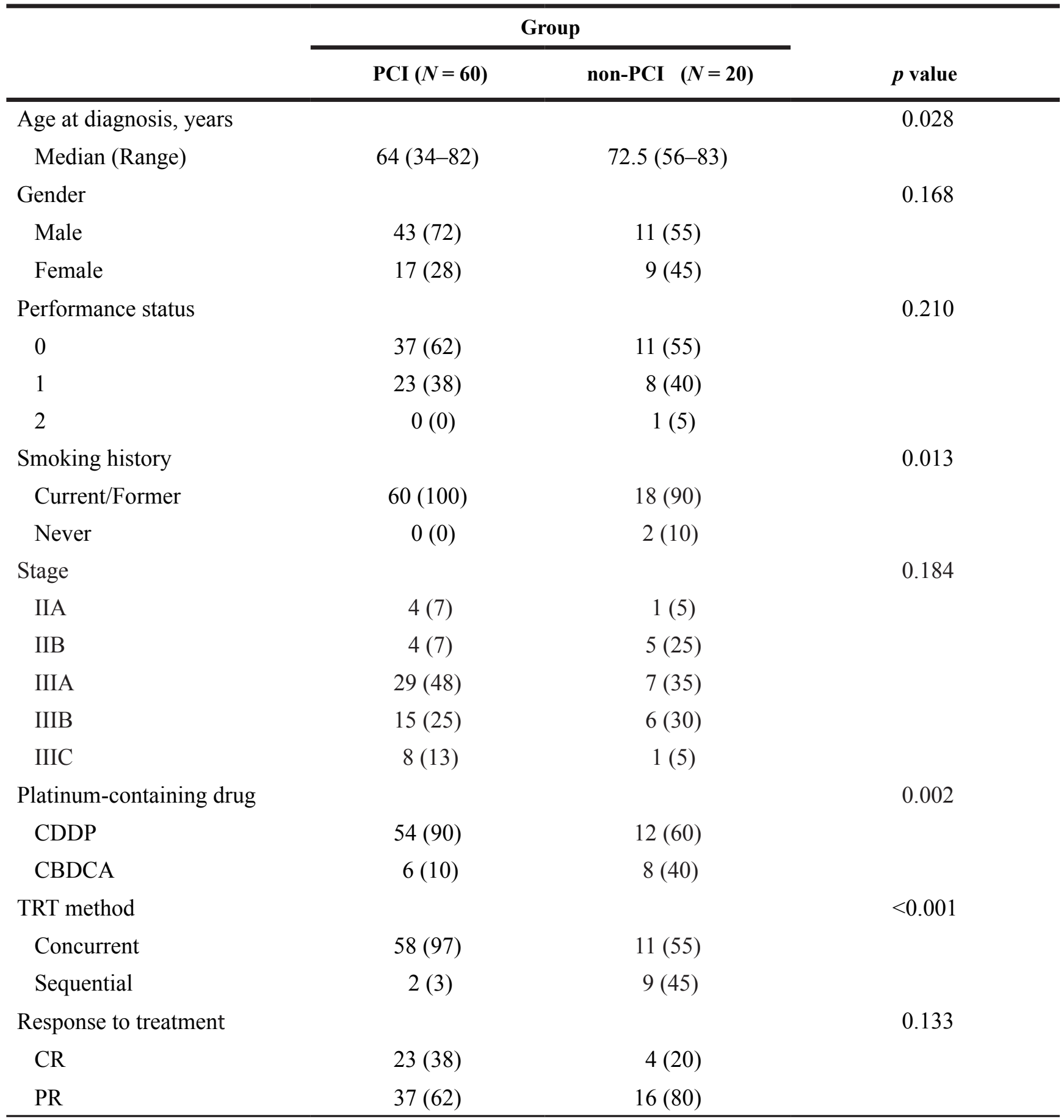

Abbreviation: PCI, prophylactic cranial irradiation; CDDP, cisplatin; CBDCA, carboplatin; CR, complete response; PR, partial response.

chemotherapy leads to poor patient prognosis [24, 25]. In our study, the age and frequency of sequential TRT were significantly higher in the non-PCI group than in the PCI group, but no significant difference was observed in OS. Moreover, BM incidence and survival between patients who underwent and did not undergo PCI were not significantly different if patients received adequate stereotactic irradiation and brain MRI [26].
Meanwhile, the long-term side effects of PCI are concerning. Several phase III trials showed that PCI caused a deterioration of neuropsychological and cognitive functions [27-29]. PCI is also a risk factor of leukoencephalopathy [30,31]. Elderly patients aged $>65$ years had PCI-induced neurotoxicity more frequently than younger patients [32]. PCI cannot significantly improve OS or brain metastasis-free survival among elderly 


\begin{tabular}{|c|c|c|c|}
\hline & \multicolumn{2}{|c|}{ Group } & \multirow[b]{2}{*}{$p$ value } \\
\hline & $\operatorname{PCI}(N=19)$ & non-PCI $(N=19)$ & \\
\hline Age at diagnosis, years & & & 0.429 \\
\hline Median & $72(56-81)$ & $71(56-82)$ & \\
\hline Gender & & & 1 \\
\hline Male & $12(68)$ & $11(58)$ & \\
\hline Female & $7(32)$ & $8(42)$ & \\
\hline Performance status & & & 1 \\
\hline 0 & $12(63)$ & $11(58)$ & \\
\hline 1 & $7(37)$ & $7(37)$ & \\
\hline 2 & $0(0)$ & $1(5)$ & \\
\hline Smoking history & & & 0.487 \\
\hline Current/Former & $19(100)$ & $17(89)$ & \\
\hline Never & $0(0)$ & $2(11)$ & \\
\hline Stage & & & 0.270 \\
\hline IIA & $3(16)$ & $1(5)$ & \\
\hline IIB & $1(5)$ & $5(26)$ & \\
\hline IIIA & $10(53)$ & $6(32)$ & \\
\hline IIIB & $4(21)$ & $6(32)$ & \\
\hline IIIC & $1(5)$ & $1(5)$ & \\
\hline Platinum-containing drug & & & 0.476 \\
\hline CDDP & $15(79)$ & $12(63)$ & \\
\hline CBDCA & $4(21)$ & $7(37)$ & \\
\hline TRT method & & & 0.063 \\
\hline Concurrent & $17(89)$ & $11(58)$ & \\
\hline Sequential & $2(11)$ & $8(42)$ & \\
\hline Response to treatment & & & 0.170 \\
\hline $\mathrm{CR}$ & $9(47)$ & $4(21)$ & \\
\hline PR & $10(53)$ & $15(79)$ & \\
\hline
\end{tabular}

Abbreviation: PCI, prophylactic cranial irradiation; CDDP, cisplatin; CBDCA, carboplatin; CR, complete response; PR, partial response.

patients with LD-SCLC aged $\geq 70$ years, particularly those with large tumors [33]. As such, PCI in elderly patients with LD-SCLC should be carefully considered, particularly for adequate BM management.

Our study has some limitations. First, it was a single-institutional study, and we cannot avoid selection bias. The frequency of CBDCA-based chemotherapy was higher in the non-PCI than in the PCI group. However, a meta-analysis of 4 randomized trials in patients with
SCLC showed no differences in survival between CDDP and CBDCA [34]. ECOG-PS and TNM classification stage of SCLC was similar in both groups. In addition, all patients received the standard regimen for chemotherapy and TRT or PCI dose. Therefore, our study has high external validity for real-world clinical settings. Second, the study population was small, particularly that of the non-PCI group, because of the low incidence of LDSCLC. This was because the current standard of care in 
patients with LD-SCLC who have a good response to initial chemoradiotherapy is to receive PCI, although no individual randomized trial with PCI has demonstrated a significant OS prolongation for patients with LD-SCLC. Only few reports on patients with LD-SCLC who received standard chemoradiotherapy without PCI are available [35-37]. However, no studies about the clinical benefits of PCI in patients with LD-SCLC confirmed with no BM on MRI have been conducted. Third, patient prognosis was better in our study than that in previous reports [38]. This may be because the current standard assessment with

A

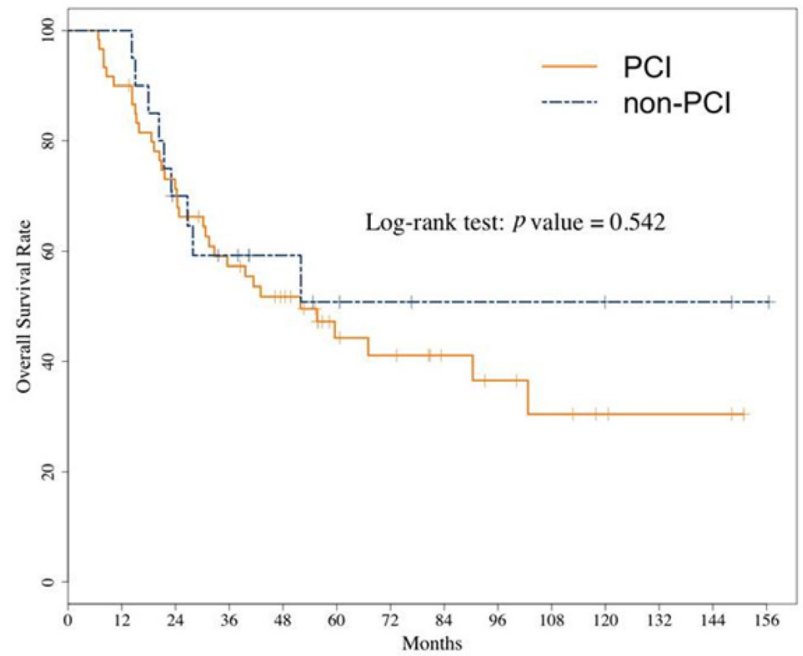

contrast-enhanced CT or PET/CT and MRI in pre- and post-treatment follow-up are more accurate. Recently, a Japanese randomized phase 3 study (JCOG0202) reported a median OS of 3.2 years (95\% CI: $2.4-4.1)$ in patients with LD-SCLC treated with etoposide and CDDP plus concurrent accelerated-hyper fractionation-TRT [39]. Patient prognosis in our study was consistent with that of JCOG0202, considering our study excluded the patients with brain metastases during the initial treatment period. Finally, some cases were censored because of patients' request to transfer to another hospital to receive best
B

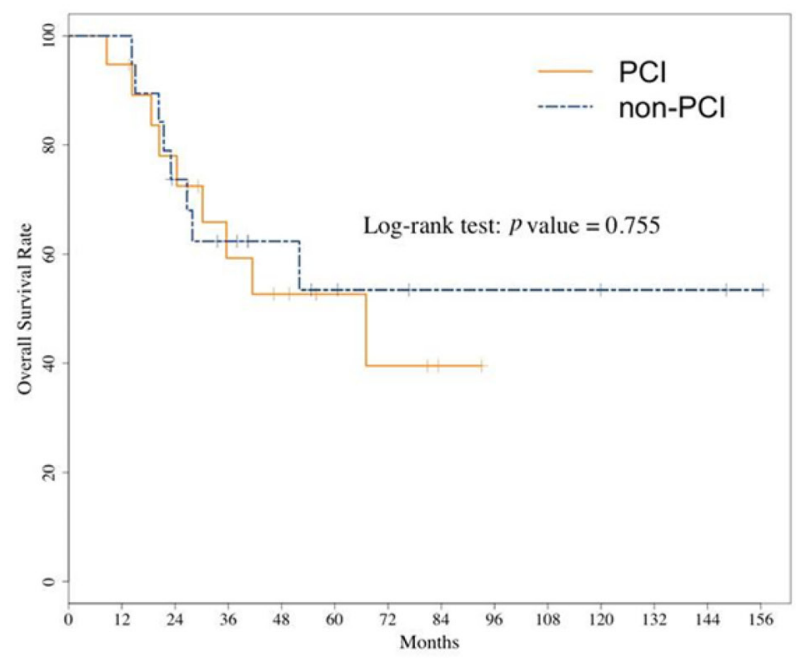

Figure 2: Overall survival curve in the unmatched overall cohort (A) and in the propensity score-matched cohort (B). OS was not significantly different between the PCI and the non-PCI group in the unmatched overall cohort (A). After propensity score matching, PCI was not associated with OS prolongation (B). Abbreviation: OS, overall survival; PCI, prophylactic cranial irradiation.

A

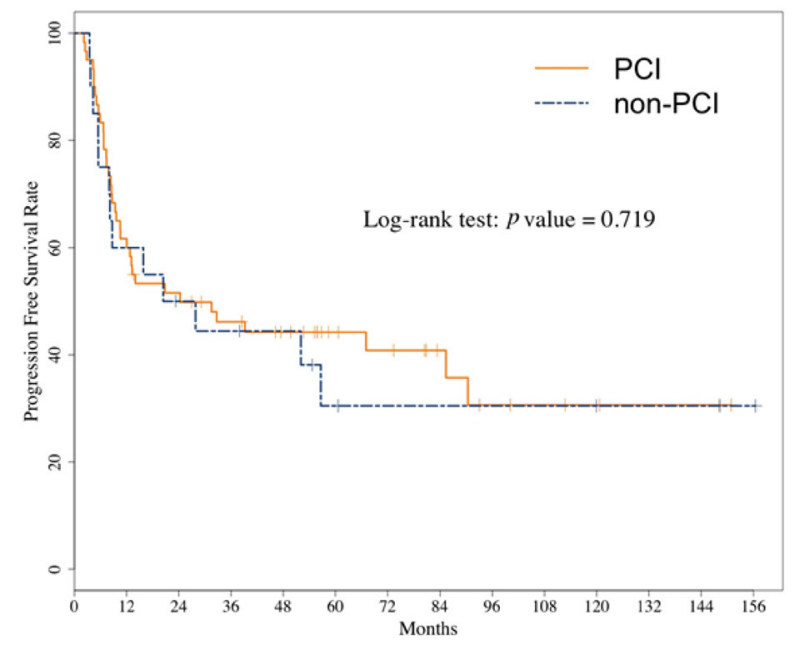

B

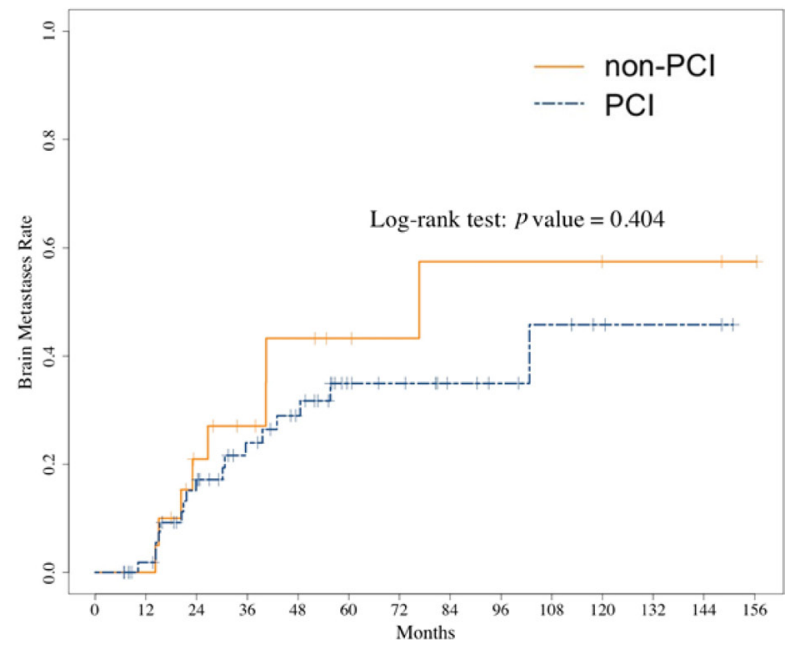

Figure 3: Progression-free survival (A) and cumulative incidence of brain metastases (B) in the unmatched overall cohort. No differences were observed in the PFS and cumulative incidence of BM between the PCI and the non-PCI group. Abbreviation: PCI, prophylactic cranial irradiation; PFS, Progression-free survival; BM, brain metastases. 


\begin{tabular}{|c|c|c|}
\hline \multirow[b]{3}{*}{ Disease recurrence $^{* 1}$} & \multicolumn{2}{|c|}{ Group } \\
\hline & $\operatorname{PCI}(N=60)$ & non-PCI $(N=20)$ \\
\hline & $28(46.7 \%)$ & $10(50 \%)$ \\
\hline Second-line chemotherapy & $27^{* 2}$ & 7 \\
\hline Single agents & 14 & 4 \\
\hline Platinum-based doublet & 13 & 3 \\
\hline Third-line chemotherapy & 19 & 6 \\
\hline Single agents & 14 & 5 \\
\hline Platinum-based doublet & 5 & 1 \\
\hline Fourth-line chemotherapy & 11 & 5 \\
\hline Single agents & 10 & 4 \\
\hline Platinum-based doublet & 1 & 1 \\
\hline Brain metastases recurrences & $17(28.3 \%)$ & $8(40 \%)$ \\
\hline Radiation therapy for BM recurrences & 11 & 6 \\
\hline WBRT & 2 & 6 \\
\hline WBRT + SRT & 1 & 0 \\
\hline WBRT + SRS & 1 & 0 \\
\hline SRT & 4 & 0 \\
\hline SRS & 3 & 0 \\
\hline Chemotherapy for BM recurrences & 4 & 1 \\
\hline Untreated & 1 & 0 \\
\hline Unknown & 1 & 1 \\
\hline
\end{tabular}

${ }^{* 1}$ Brain metastases recurrences are included in disease progression.

${ }^{* 2} 1$ patient out of the 28 who have disease recurrences received thoracic radiation therapy for local recurrence.

Abbreviation: PCI, prophylactic cranial irradiation; BM, brain metastases; WBRT, whole brain radiation therapy; SRT, Stereotactic radiotherapy; SRS, Stereotactic radiosurgery.

supportive care. However, the median observation period of our study was more than 3 years, and no differences were observed in both groups.

Despite several limitations, our study is valuable because this is the first study in terms of asymptomatic BM during treatment in patients with LD-SCLC receiving PCI.

\section{CONCLUSIONS}

The results of this retrospective study suggest that PCI may not only have a clinical benefit for survival but also the BM incidence in patients with LD-SCLC confirmed with no BM before PCI, even if patients achieve a good response to definitive chemoradiotherapy. Therefore, performing PCI should be carefully considered.
Further prospective studies are warranted to identify the clinical benefit of PCI in this population.

\section{PATIENTS AND METHODS}

\section{Patients}

We retrospectively evaluated the efficacy of PCI in patients with LD-SCLC. LD-SCLC was defined as disease confined to one hemithorax including local extension and ipsilateral hilar, bilateral mediastinal, and supraclavicular lymph node metastases, which can be encompassed by a single radiotherapy port. Patients with malignant pleural effusion, defined as ED-SCLC, were excluded. Staging 
was performed via CT, MRI, bone scan, and positronemission tomography (PET)/CT. Patients with LD-SCLC who achieved $\mathrm{CR}$ or $\mathrm{PR}$ and have no BM confirmed via MRI after initial chemoradiotherapy at Shizuoka Cancer Center from September 2002 to August 2015 were assessed. Patient data, including age at diagnosis, sex, ECOG-PS, smoking history, clinical stage according to the Union International for Cancer Control-TNM 8th edition, chemotherapy regimen, TRT method, best response to initial treatment, treatment with PCI or not, and outcomes were obtained from medical records. The study was approved by the Institutional Review Board of Shizuoka Cancer Center. We provided the patients the opportunity to opt out of this study.

\section{Treatment}

The patients were administered 4 cycles of platinum-based treatment regimens that mainly consisted of etoposide and CDDP or CBDCA. TRT was performed concurrently or sequentially with chemotherapy. The usual prescription dose was 45 Gy in 30 fractions, administered twice daily over a 3-week period (accelerated-hyper fractionation-TRT), except for 2 patients who were delivered 48-50 Gy in 24-25 daily fractions with a sequential conventional radiotherapy. Treatment response was defined as CR or PR according to the Response Evaluation Criteria in Solid Tumors criteria version 1.1 as assessed via CT. Brain MRI after initial treatment was necessary to confirm the absence of BM. Patients who showed BM on MRI after initial therapy or who did not undergo brain MRI were excluded. PCI was delivered at 25 Gy in 10 daily fractions to the whole brain, which is the standard for LD-SCLC [40].

\section{Statistical analysis}

We compared treatment-related characteristics between the two groups using Pearson's chi-square test or Fisher's exact test as well as nonparametric test of medians for categorical variables and unpaired student's $t$-test for continuous variables. The follow-up period was calculated from the end of the initial therapy to the date of death or the date last confirmed alive. The primary endpoint of this study was OS, defined as the interval between the end of the initial chemoradiotherapy and the date of death or the last follow-up visit. The secondary endpoints were PFS and the cumulative incidence of BM. PFS was defined as the interval between the end of the initial chemoradiotherapy and the date of any recurrences detected with any imaging modality, death, or the last follow-up visit. OS curves, PFS curves, and the cumulative incidence of BM were estimated using the Kaplan-Meier method, and the groups were compared using log-rank test. Patients who remained alive were censored. Univariate and multivariate analyses of OS were performed with the Cox proportional hazards regression model in the unmatched overall cohort. Propensity score matching was also used to balance baseline characteristics between the two groups. We calculated the propensity scores using a multiple logistic regression model that included age at diagnosis, chemotherapy regimen, and TRT method.

All $p$ values are two sided, and a value of $<0.05$ was considered statistically significant. All statistical analyses were performed using the statistical software $\mathrm{JMP}^{\circledR} 13$ (SAS Institute Inc., Cary, NC, USA) and R version 3.4.2. software (Institute for Statistics and Mathematics, Vienna, Austria).

\section{Abbreviations}

SCLC: small-cell lung cancer; ED: extensive disease; LD: limited disease; TRT: thoracic radiotherapy; CDDP: cisplatin; CBDCA: carboplatin; BM: brain metastases; CR: complete response; PCI: prophylactic cranial irradiation; OS: overall survival; PR: partial response; ED-SCLC: extensive disease-small cell lung cancer; MRI: magnetic resonance imaging; CT: computed tomography; PET: positron-emission tomography; ECOGPS: Eastern Cooperative Oncology Group Performance Status; PFS: progression-free survival.

\section{Author contributions}

N.M and K.W designed the study, collected data and wrote the manuscript. K.O and T.T participated in the study designing. K.O and K.M analyzed the data. All authors carried out the interpretation of data and drafted the manuscript. All authors read and approved the final manuscript.

\section{ACKNOWLEDGMENTS}

\author{
Not applicable.
}

\section{CONFLICTS OF INTEREST}

KW received honoraria from Taiho Pharmaceutical Co., Ltd., Boehringer Ingelheim, and Ono Pharmaceutical Co., Ltd. HK received honoraria from Eli Lilly Japan K.K. and Taiho Pharmaceutical Co., Ltd. SO received honoraria from Chugai Pharmaceutical Co., Ltd., Ono Pharmaceutical Co., Ltd., AstraZeneca, Taiho Pharmaceutical Co., Ltd., and Boehringer Ingelheim. KN received honoraria from Eli Lilly Japan K.K., Ono Pharmaceutical Co., Ltd., Mochida Pharmaceutical Co., Ltd., and Taiho Pharmaceutical Co., Ltd. AO received honoraria from Taiho Pharmaceutical Co., Ltd., Chugai Pharmaceutical Co., Ltd., and Takeda Pharmaceutical Co., Ltd. H. Kenmotsu received honoraria from Ono Pharmaceutical Co., Ltd., AstraZeneca, Boehringer Ingelheim, Eli Lilly Japan K.K., Chugai 
Pharmaceutical Co., Ltd., Bristol-Myers Squibb Co., Ltd., Taiho Pharmaceutical Co., Ltd., and Kyowa Hakko Kirin and research funding from AstraZeneca and Boehringer Ingelheim. TN received honoraria from Ono Pharmaceutical Co., Ltd. HM received honoraria from Chugai Pharmaceutical Co., Ltd., Pfizer, Novartis, Boehringer Ingelheim, Taiho Pharmaceutical Co., Ltd., AstraZeneca, Eli Lilly Japan K.K., Ono Pharmaceutical Co., Ltd., Bristol-Myers, and Astellas Pharma Inc. ME received honoraria from Ono Pharmaceutical Co., Ltd. TT received honoraria from Ono Pharmaceutical Co., Ltd., AstraZeneca, Boehringer Ingelheim, Pfizer, Eli Lilly Japan K.K., and Chugai Pharmaceutical Co., Ltd. and research funding from Ono Pharmaceutical Co., Ltd., AstraZeneca, Eli Lilly Japan K.K., Chugai Pharmaceutical Co., Ltd., Pfizer, Takeda Pharmaceutical, Taiho Pharmaceutical Co., Ltd., and MSD K.K. All remaining authors declare no conflicts of interest in the writing of this article.

\section{FUNDING}

This research did not receive any specific grant from funding agencies in the public, commercial, or not-forprofit sectors.

\section{REFERENCES}

1. Govindan R, Page N, Morgensztern D, Read W, Tierney R, Vlahiotis A, Spitznagel EL, Piccirillo J. Changing epidemiology of small-cell lung cancer in the United States over the last 30 years: analysis of the surveillance, epidemiologic, and end results database. J Clin Oncol. 2006; 24:4539-44. https://doi.org/10.1200/JCO.2005.04.4859.

2. Nicholson AG, Chansky K, Crowley J, Beyruti R, Kubota K, Turrisi A, Eberhardt WE, van Meerbeeck J, RamiPorta R, and Staging and Prognostic Factors Committee, and Advisory Boards, and Participating Institutions. The International Association for the Study of Lung Cancer Lung Cancer Staging Project: Proposals for the Revision of the Clinical and Pathologic Staging of Small Cell Lung Cancer in the Forthcoming Eighth Edition of the TNM Classification for Lung Cancer. J Thorac Oncol. 2016; 11:300-11. https://doi.org/10.1016/j.jtho.2015.10.008.

3. Shepherd FA, Crowley J, Van Houtte P, Postmus PE, Carney D, Chansky K, Shaikh Z, Goldstraw P. The International Association for the Study of Lung Cancer lung cancer staging project: proposals regarding the clinical staging of small cell lung cancer in the forthcoming (seventh) edition of the tumor, node, metastasis classification for lung cancer. J Thorac Oncol. 2007; 2:1067-77. https:// doi.org/10.1097/JTO.0b013e31815bdc0d.

4. Pignon JP, Arriagada R, Ihde DC, Johnson DH, Perry MC, Souhami RL, Brodin O, Joss RA, Kies MS, Lebeau B, Onoshi T, Østerlind K, Tattersall MH, Wagner H. A metaanalysis of thoracic radiotherapy for small-cell lung cancer.
N Engl J Med. 1992; 327:1618-24.https://doi.org/10.1056/ NEJM199212033272302.

5. Warde P, Payne D. Does thoracic irradiation improve survival and local control in limited-stage small-cell carcinoma of the lung? A meta-analysis. J Clin Oncol. 1992; 10:890-95. https:// doi.org/10.1200/JCO.1992.10.6.890.

6. Sundstrom S, Bremnes RM, Kaasa S, Aasebo U, Hatlevoll R, Dahle R, Boye N, Wang M, Vigander T, Vilsvik J, Skovlund E, Hannisdal E, Aamdal S. Cisplatin and etoposide regimen is superior to cyclophosphamide, epirubicin, and vincristine regimen in small-cell lung cancer: results from a randomized phase III trial with 5 years' follow-up. J Clin Oncol. 2002; 20:4665-72. https://doi.org/10.1200/JCO.2002.12.111.

7. Karam I, Jiang SY, Khaira M, Lee CW, Schellenberg D. Outcomes of small cell lung cancer patients treated with cisplatin-etoposide versus carboplatin-etoposide. Am J Clin Oncol. 2015; 38:51-54. https://doi.org/10.1097/ COC.0b013e31828aab2a.

8. Arriagada R, Le Chevalier T, Borie F, Riviere A, Chomy P, Monnet I, Tardivon A, Viader F, Tarayre M, Benhamou S. Prophylactic cranial irradiation for patients with small-cell lung cancer in complete remission. J Natl Cancer Inst. 1995; 87:183-90. https://doi.org/10.1093/jnci/87.3.183.

9. Kristensen CA, Kristjansen PE, Hansen HH. Systemic chemotherapy of brain metastases from small-cell lung cancer: a review. J Clin Oncol. 1992; 10:1498-502. https:// doi.org/10.1200/JCO.1992.10.9.1498.

10. Manapov F, Klautke G, Fietkau R. Prevalence of brain metastases immediately before prophylactic cranial irradiation in limited disease small cell lung cancer patients with complete remission to chemoradiotherapy: a single institution experience. J Thorac Oncol. 2008; 3:652-55. https://doi. org/10.1097/JTO.0b013e3181757a76.

11. Aroney RS, Aisner J, Wesley MN, Whitacre MY, Van Echo DA, Slawson RG, Wiernik PH. Value of prophylactic cranial irradiation given at complete remission in small cell lung carcinoma. Cancer Treat Rep. 1983; 67:675-82.

12. Ohonoshi T, Ueoka H, Kawahara S, Kiura K, Kamei H, Hiraki Y, Segawa Y, Hiraki S, Kimura I. Comparative study of prophylactic cranial irradiation in patients with small cell lung cancer achieving a complete response: a long-term follow-up result. Lung Cancer. 1993; 10:47-54. https://doi. org/10.1016/0169-5002(93)90308-K.

13. Gregor A, Cull A, Stephens RJ, Kirkpatrick JA, Yarnold JR, Girling DJ, Macbeth FR, Stout R, Machin D. Prophylactic cranial irradiation is indicated following complete response to induction therapy in small cell lung cancer: results of a multicentre randomised trial. United Kingdom Coordinating Committee for Cancer Research (UKCCCR) and the European Organization for Research and Treatment of Cancer (EORTC). Eur J Cancer. 1997; 33:1752-58. https:// doi.org/10.1016/S0959-8049(97)00135-4.

14. Laplanche A, Monnet I, Santos-Miranda JA, Bardet E, Le Pechoux C, Tarayre M, Arriagada R. Controlled clinical trial 
of prophylactic cranial irradiation for patients with smallcell lung cancer in complete remission. Lung Cancer. 1998; 21:193-201. https://doi.org/10.1016/S0169-5002(98)00056-7.

15. Auperin A, Arriagada R, Pignon JP, Le Pechoux C, Gregor A, Stephens RJ, Kristjansen PE, Johnson BE, Ueoka H, Wagner H, Aisner J. Prophylactic cranial irradiation for patients with small-cell lung cancer in complete remission. Prophylactic Cranial Irradiation Overview Collaborative Group. N Engl J Med. 1999; 341:476-84. https://doi. org/10.1056/NEJM199908123410703.

16. Meert AP, Paesmans M, Berghmans T, Martin B, Mascaux C, Vallot F, Verdebout JM, Lafitte JJ, Sculier JP. Prophylactic cranial irradiation in small cell lung cancer: a systematic review of the literature with meta-analysis. BMC Cancer. 2001; 1:5. https://doi.org/10.1186/1471-2407-1-5.

17. Rudin CM, Ismaila N, Hann CL, Malhotra N, Movsas B, Norris K, Pietanza MC, Ramalingam SS, Turrisi AT 3rd, Giaccone G. Treatment of small-cell lung cancer: American Society of Clinical Oncology endorsement of the American College of Chest Physicians Guideline. J Clin Oncol. 2015; 33:4106-11. https://doi.org/10.1200/JCO.2015.63.7918.

18. Takahashi T, Yamanaka T, Seto T, Harada H, Nokihara H, Saka H, Nishio M, Kaneda H, Takayama K, Ishimoto O, Takeda K, Yoshioka H, Tachihara M, et al. Prophylactic cranial irradiation versus observation in patients with extensive-disease small-cell lung cancer: a multicentre, randomised, open-label, phase 3 trial. Lancet Oncol. 2017; 18:663-71. https://doi.org/10.1016/S1470-2045(17)30230-9.

19. Schellinger PD, Meinck HM, Thron A. Diagnostic accuracy of MRI compared to CCT in patients with brain metastases. J Neurooncol. 1999; 44:275-81. https://doi. org/10.1023/A:1006308808769.

20. Zhang W, Jiang W, Luan L, Wang L, Zheng X, Wang G. Prophylactic cranial irradiation for patients with smallcell lung cancer: a systematic review of the literature with meta-analysis. BMC Cancer. 2014; 14:793. https://doi. org/10.1186/1471-2407-14-793.

21. Seute T, Leffers P, ten Velde GP, Twijnstra A. Detection of brain metastases from small cell lung cancer: consequences of changing imaging techniques (CT versus MRI). Cancer. 2008; 112:1827-34. https://doi.org/10.1002/cncr.23361.

22. Slotman B, Faivre-Finn C, Kramer G, Rankin E, Snee M, Hatton M, Postmus P, Collette L, Musat E, Senan S. Prophylactic cranial irradiation in extensive small-cell lung cancer. N Engl J Med. 2007; 357:664-72. https://doi. org/10.1056/NEJMoa071780.

23. Alberg AJ, Brock MV, Ford JG, Samet JM, Spivack SD. Epidemiology of lung cancer: diagnosis and management of lung cancer, 3rd ed: American College of Chest Physicians evidence-based clinical practice guidelines. Chest. 2013; 143:e1S-e29S. https://doi.org/10.1378/chest.12-2345..

24. Pijls-Johannesma M, De Ruysscher D, Vansteenkiste J, Kester A, Rutten I, Lambin P. Timing of chest radiotherapy in patients with limited stage small cell lung cancer: a systematic review and meta-analysis of randomised controlled trials.
Cancer Treat Rev. 2007; 33:461-73. https://doi.org/10.1016/j. ctrv.2007.03.002.

25. De Ruysscher D, Lueza B, Le Pechoux C, Johnson DH, O’Brien M, Murray N, Spiro S, Wang X, Takada M, Lebeau B, Blackstock W, Skarlos D, Baas P, et al. Impact of thoracic radiotherapy timing in limited-stage smallcell lung cancer: usefulness of the individual patient data meta-analysis. Ann Oncol. 2016; 27:1818-28. https:/doi. org/10.1093/annonc/mdw263.

26. Ozawa Y, Omae M, Fujii M, Matsui T, Kato M, Sagisaka S, Asada K, Karayama M, Shirai T, Yasuda K, Nakamura Y, Inui $\mathrm{N}$, Yamada $\mathrm{K}$, et al. Management of brain metastasis with magnetic resonance imaging and stereotactic irradiation attenuated benefits of prophylactic cranial irradiation in patients with limited-stage small cell lung cancer. BMC Cancer. 2015; 15:589. https://doi.org/10.1186/s12885-015-1593-2.

27. Le Pechoux C, Laplanche A, Faivre-Finn C, Ciuleanu T, Wanders R, Lerouge D, Keus R, Hatton M, Videtic GM, Senan S, Wolfson A, Jones R, Arriagada R, et al. Clinical neurological outcome and quality of life among patients with limited small-cell cancer treated with two different doses of prophylactic cranial irradiation in the intergroup phase III trial (PCI99-01, EORTC 22003-08004, RTOG 0212 and IFCT 99-01). Ann Oncol. 2011; 22:1154-63. https://doi.org/10.1093/ annonc/mdq576.

28. Wolfson AH, Bae K, Komaki R, Meyers C, Movsas B, Le Pechoux C, Werner-Wasik M, Videtic GM, Garces YI, Choy H. Primary analysis of a phase II randomized trial Radiation Therapy Oncology Group (RTOG) 0212: impact of different total doses and schedules of prophylactic cranial irradiation on chronic neurotoxicity and quality of life for patients with limited-disease small-cell lung cancer. Int J Radiat Oncol Biol Phys. 2011; 81:77-84. https://doi. org/10.1016/j.jirobp.2010.05.013.

29. Gondi V, Paulus R, Bruner DW, Meyers CA, Gore EM, Wolfson A, Werner-Wasik M, Sun AY, Choy H, Movsas B. Decline in tested and self-reported cognitive functioning after prophylactic cranial irradiation for lung cancer: pooled secondary analysis of Radiation Therapy Oncology Group randomized trials 0212 and 0214. Int J Radiat Oncol Biol Phys. 2013; 86:656-64. https://doi.org/10.1016/j.ijrobp.2013.02.033.

30. Frytak S, Shaw JN, O’Neill BP, Lee RE, Eagan RT, Shaw EG, Richardson RL, Coles DT, Jett JR. Leukoencephalopathy in small cell lung cancer patients receiving prophylactic cranial irradiation. Am J Clin Oncol. 1989; 12:27-33. https://doi. org/10.1097/00000421-198902000-00007.

31. Fonseca R, O’Neill BP, Foote RL, Grill JP, Sloan JA, Frytak S. Cerebral toxicity in patients treated for small cell carcinoma of the lung. Mayo Clin Proc. 1999; 74:461-65. https://doi. org/10.1016/S0025-6196(11)65123-9.

32. Nakahara Y, Takagi Y, Okuma Y, Hosomi Y, Okamura T, Shibuya M, Masuda N. Neurotoxicity due to prophylactic cranial irradiation for small-cell lung cancer: A retrospective analysis. Mol Clin Oncol. 2015; 3:1048-52. https://doi. org/10.3892/mco.2015.581. 
33. Farooqi AS, Holliday EB, Allen PK, Wei X, Cox JD, Komaki R. Prophylactic cranial irradiation after definitive chemoradiotherapy for limited-stage small cell lung cancer: do all patients benefit? Radiother Oncol. 2017; 122:307-12. https://doi.org/10.1016/j.radonc.2016.11.012.

34. Rossi A, Di Maio M, Chiodini P, Rudd RM, Okamoto H, Skarlos DV, Fruh M, Qian W, Tamura T, Samantas E, Shibata T, Perrone F, Gallo C, et al. Carboplatin- or cisplatinbased chemotherapy in first-line treatment of small-cell lung cancer: the COCIS meta-analysis of individual patient data. J Clin Oncol. 2012; 30:1692-98.https://doi.org/10.1200/ JCO.2011.40.4905.

35. Nicholls L, Keir GJ, Murphy MA, Mai T, Lehman M. Prophylactic cranial irradiation in small cell lung cancer: A single institution experience. Asia Pac J Clin Oncol. 2016; 12:415-20. https://doi.org/10.1111/ajco.12564.

36. Qiu G, Du X, Zhou X, Bao W, Chen L, Chen J, Ji Y, Wang S. Prophylactic cranial irradiation in 399 patients with limitedstage small cell lung cancer. Oncol Lett. 2016; 11:2654-60. https://doi.org/10.3892/ol.2016.4231.

37. Sakaguchi M, Maebayashi T, Aizawa T, Ishibashi N, Saito T. Treatment outcomes of patients with small cell lung cancer without prophylactic cranial irradiation. J Thorac Dis. 2016; 8:2571-79. https://doi.org/10.21037/jtd.2016.08.73.
38. Koinis F, Kotsakis A, Georgoulias V. Small cell lung cancer (SCLC): no treatment advances in recent years. Transl Lung Cancer Res. 2016; 5:39-50. https://doi.org/10.3978/j. issn.2218-6751.2016.01.03

39. Kubota K, Hida T, Ishikura S, Mizusawa J, Nishio M, Kawahara M, Yokoyama A, Imamura F, Takeda K, Negoro S, Harada M, Okamoto H, Yamamoto N, et al. Etoposide and cisplatin versus irinotecan and cisplatin in patients with limited-stage small-cell lung cancer treated with etoposide and cisplatin plus concurrent accelerated hyperfractionated thoracic radiotherapy (JCOG0202): a randomised phase 3 study. Lancet Oncol. 2014; 15:106-13.https://doi.org/10.1016/ S1470-2045(13)70511-4.

40. Le Pechoux C, Dunant A, Senan S, Wolfson A, Quoix E, Faivre-Finn C, Ciuleanu T, Arriagada R, Jones R, Wanders R, Lerouge D, Laplanche A. Standard-dose versus higher-dose prophylactic cranial irradiation (PCI) in patients with limitedstage small-cell lung cancer in complete remission after chemotherapy and thoracic radiotherapy (PCI 99-01, EORTC 22003-08004, RTOG 0212, and IFCT 99-01): a randomised clinical trial. Lancet Oncol. 2009; 10:467-74. https://doi. org/10.1016/S1470-2045(09)70101-9. 